\title{
Novos táxons de Hemilophini (Coleoptera, Cerambycidae, Lamiinae) das Américas
}

\author{
Ubirajara R. Martins ${ }^{1} \&$ Maria Helena M. Galileo ${ }^{2}$
}

1. Museu de Zoologia, Universidade de São Paulo, Caixa Postal 42494, 04218-970 São Paulo, SP, Brasil. (urmsouza@usp.br)

2. Museu de Ciências Naturais, Fundação Zoobotânica do Rio Grande do Sul, Caixa Postal 1188, 90001-970 Porto Alegre, RS, Brasil. (galileo@fzb.rs.gov.br)

\begin{abstract}
New taxa of Hemilophini (Coleoptera, Cerambycidae, Lamiinae) of the Americas. The new genus Mexicoscylus is described to include: M. rosae sp. nov., type species of the genus, and M. bivittatus (Gahan, 1892), comb. nov. both from Mexico. A key to the species of Mexicoscylus is added. More three species are described: Cotycuara villosa sp. nov., from Costa Rica; Phoebe parvimacula sp. nov., from Bolivia and Adesmus beruri sp. nov., from Brazil (Amazonas). All new species are illustrated.
\end{abstract}

KEYWORDS. Adesmus, Cotycuara, Mexicoscylus, Phoebe, taxonomy.

RESUMO. Descreve-se o gênero Mexicoscylus para incluir M. rosae sp. nov., do México, espécie-tipo do gênero, e M. bivittatus (Gahan, 1892), comb. nov. Acrescenta-se chave para as espécies de Mexicoscylus. Mais três espécies são descritas: Cotycuara villosa sp. nov., da Costa Rica; Phoebe parvimacula sp. nov., da Bolívia e Adesmus beruri sp. nov., do Brasil (Amazonas). Todas as espécies novas são ilustradas.

PALAVRAS-CHAVE. Adesmus, Cotycuara, Mexicoscylus, Phoebe, taxonomia.

A tribo Hemilophini reúne 123 gêneros (MonNé \& BeZArk, 2009). Propõe-se um gênero novo que será comparado com Sybaguasu Martins \& Galileo, 1991 e Lamacoscylus Martins \& Galileo, 1991; esses gêneros foram propostos para alocar espécies impropriamente incluídas em Malacoscylus Thomson, 1868 (Martins \& Galileo, 1991).

O gênero Cotycuara, onde é incluída uma nova espécie, foi proposto por Galileo \& Martins (2004) para C. albomarginata (Gahan, 1892), ocorrente na Costa Rica e no Panamá. Galileo \& Martins (2005) descreveram mais duas espécies (C. viridis da Costa Rica e $C$. crinita do Panamá) e publicaram uma chave para as espécies.

O gênero Phoebe Audinet-Serville, 1835, onde se insere mais uma nova espécie, foi revisto por MARTINS \& Galileo (1998). Martins \& Galileo (2004) acrescentaram $P$. alba. As quinze espécies conhecidas de Phoebe ocorrem desde o México até a Argentina (Monné \& BEZARK, 2009).

O gênero Adesmus Lepeletier \& A.-Serville, 1825 foi revisto por Galileo \& Martins (1999) que apresentaram uma chave para as 43 espécies conhecidas. Atualmente, o gênero contém 62 espécies (Monné \& BEZARK, 2009) e ora acrescenta-se mais uma.

O material estudado pertence às seguintes coleções: American Coleoptera Museum, San Antonio, Texas (ACMS); Instituto Nacional de Pesquisas da Amazônia, Manaus (INPA); Museo Noel Kempff Mercado, Santa Cruz de La Sierra (MNKM).

\section{Mexicoscylus gen. nov.}

Etimologia. Composição das palavras México, hábitat das espécies e scylus terminação do nome genérico Malacoscylus. Gênero masculino.

Espécie tipo. Mexicoscylus rosae sp. nov.

Cabeça moderadamente convexa no vértice. Olhos normais, estreitamento entre lobos oculares com três fileiras de omatídios; lobos oculares superiores tão distantes entre si quanto o triplo da largura de um lobo. Antenas (fêmeas) com onze artículos atingem pouco além do meio dos élitros ou quase atingem o ápice elitral. Escapo cilíndrico sem curvatura basal; ápice sem cicatriz, inteiramente revestido por pubescência curta e densa; margem interna com franja de pelos longos. Antenômeros III e IV ligeiramente engrossados para o ápice com pequeno tufo de pelos.

Protórax subquadrangular, lados sem tubérculo. Pronoto regularmente convexo. Processo prosternal muito estreito entre as procoxas.

Élitros longos, com quíntuplo do comprimento do protórax; lados pouco estreitados para o ápice. Úmeros ortogonais; carena umeral única, quase atinge a extremidade do élitro.

Metafêmures atingem o meio do urosternito III. Comprimento dos metatarsômeros I a $\mathrm{V}$ em conjunto igual a 3/4 do comprimento das metatíbias. Garras tarsais com dentes subiguais em comprimento.

Discussão. Mexicoscylus gen. nov. assemelha-se a Lamacoscylus Martins \& Galileo, 1991 e Sybaguasu Martins \& Galileo, 1991, pelos lobos oculares superiores afastados entre si e pelo antenômero IV tão longo ou apenas mais longo que o III. Em Malacoscylus, os lobos oculares superiores são próximos entre si e o antenômero IV tem menos da metade do comprimento do III.

Em Lamacoscylus, o antenômero III apresenta franja de pelos densos e élitros com carenas dorsais. 
Sybaguasu apresenta escapo com curvatura basal e élitros com espículo externo; em várias espécies, a fronte dos machos é projetada. Essas características não são encontradas em Mexicoscylus. Além disso, os antenômeros III e IV têm tegumento amarelado em grande extensão da base e a ponta castanho-escura, característica inexistente em Lamacoscylus e Sybaguasu.

\section{Chave para as espécies de Mexicoscylus}

1. Extremidades elitrais cortadas em curva com espinho externo; ápice das antenas das fêmeas aproxima-se da ponta dos élitros; antenômero III linear (Fig. 1). México (Oaxaca) M. rosae sp. nov.

2. Extremidades elitrais arredondadas; antenas das fêmeas apenas ultrapassam o meio dos élitros; antenômero III levemente engrossado. México (Guerrero) ....... M. bivittatus (Gahan, 1892)

\section{Mexicoscylus rosae sp. nov.}

(Fig. 1)

Etimologia. O nome é uma homenagem a Rejane Rosa, Museu de Ciências Naturais, Fundação Zoobotânica do Rio Grande do Sul pela arte de ilustrar os cerambicídeos.

Tegumento em geral acastanhado, genas, gula e margens elitrais até o sexto apical, base da face interna das coxas, castanho-alaranjadas. Fronte e genas com pubescência amarelada, esparsa; lobos oculares inferiores com 0,6 vezes o comprimento das genas. Região entre os tubérculos anteníferos com pubescência esbranquiçada. Vértice com pubescência amarelo-acastanhada, esparsa; a cada lado, faixa longitudinal, oblíqua da margem posterior do lobo ocular até a base, de pubescência branco-amarelada, densa. Cabeça com pontuação fina, esparsa. Antenômero III amarelado com o quarto apical castanho-escuro e levemente mais engrossado; antenômero IV amarelado com anel apical castanhoescuro; antenômeros V-XI castanho-escuros com a base castanho-avermelhadas a amareladas.

Protórax com pontuação fina, esparsa, mais grossa na metade anterior dos lados do protórax. Pronoto com pubescência amarelo-acastanhada, disposta transversalmente em direção ao centro; centro da base do pronoto com pubescência levemente mais densa e esbranquiçada; a cada lado do pronoto, faixa de pubescência branco-amarelada, densa, em continuação com a dos lados do vértice. Processo mesosternal com metade da largura de uma mesocoxa. Escutelo revestido por pubescência amarelada.

Élitros cobertos por pubescência amareloacastanhada; a cada lado do dorso, justaposta à carena, faixa de pubescência branco-amarelada, densa, em continuação com a dos lados do pronoto (Fig. 1). Pontuação elitral fina, mais densa na metade basal do dorso e nos dois terços basais da declividade lateral.

Face ventral revestida por pubescência amareloacastanhada, mais densa e alaranjada numa faixa estreita junto à margem externa dos metepisternos, na metade basal dos lados do metasterno e nos lados dos urosternitos. Urosternito V (fêmea) sem modificações, mais longo que o dobro do comprimento do IV.

Dimensões em mm. Comprimento total, 12,5; comprimento do protórax, 1,9; maior largura do protórax, 2,2; comprimento elitral, 9,3; largura umeral, 3,1.

Material-tipo. Holótipo P, MÉXICO, Oaxaca: (24 mi. S, Valle Nacional, 5600 pés), 24, 25.VII.1970, E. Fisher \& P. Sullivan col. (ACMS).

Discussão. Mexicoscylus rosae sp. nov. assemelhase a $M$. bivittatus pelo corpo esbelto, pelas faixas de pubescência esbranquiçada, densa nos lados do vértice, do pronoto e do dorso dos élitros e pelo padrão de colorido dos antenômeros III e IV. Difere pelo ápice elitral com espinho marginal e pelo escapo inteiramente revestido por pubescência longa, densa. Em M. bivittatus o escapo tem pelos esparsos e o ápice elitral não tem espículo marginal.

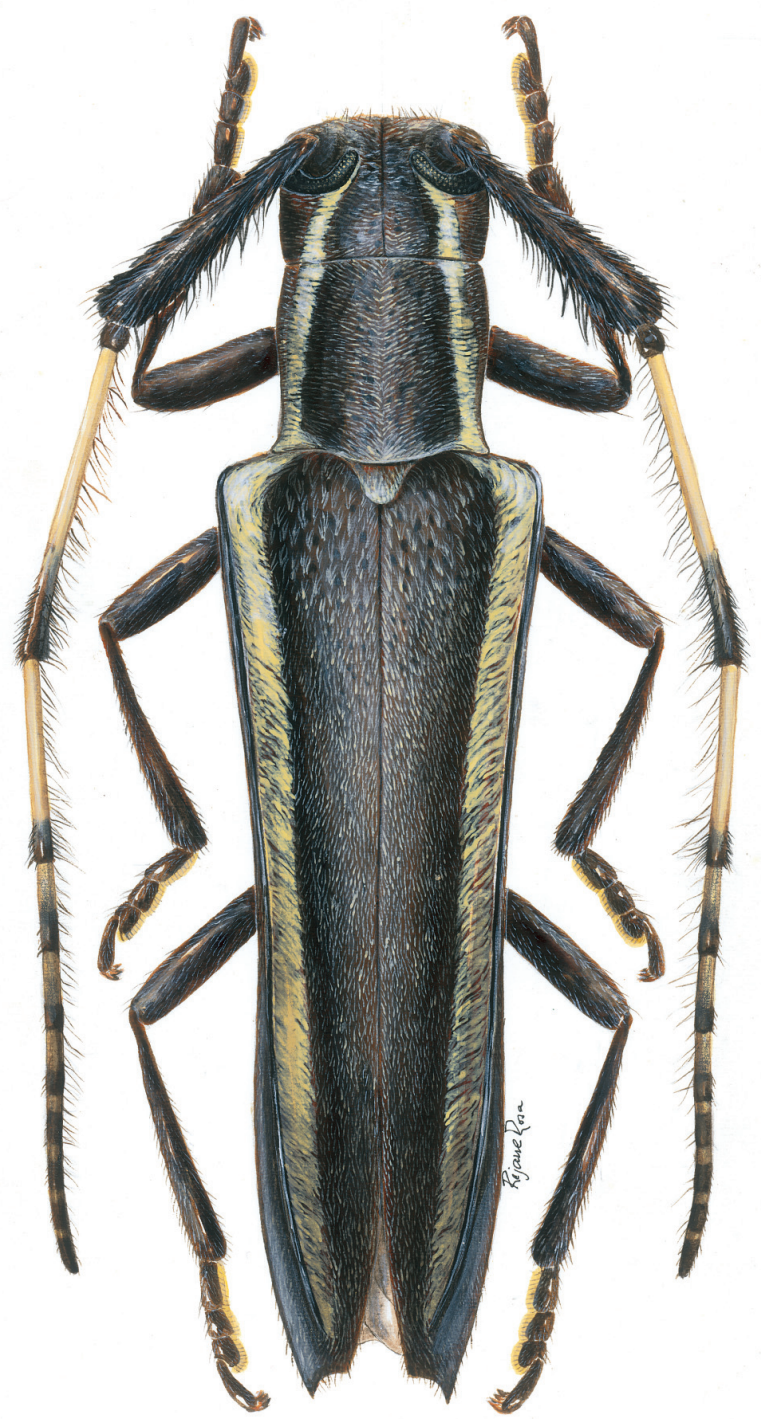

Figura 1. Mexicoscylus rosae sp. nov., holótipo fêmea, comprimento $12,5 \mathrm{~mm}$. 
Mexicoscylus bivittatus (Gahan, 1892) comb. nov.

Malacoscylus bivittatus GaHAN, 1892:272, est. 12, fig. 15. Lamacoscylus bivittatus; MarTins \& GaLILEO, 1991:628.

Martins \& Galileo (1991) transferiram provisoriamente Malacoscylus bivittatus para Lamacoscylus porque apresentava características diversas das de L. humilis (Bates, 1881) e de L. usingeri (Linsley, 1935). Examinamos a fotografia do síntipo fêmea (Bezark, 2010) de Mexicoscylus bivittatus cujas diferenças com $M$. rosae estão reproduzidas na chave.

Discussão. Ver sob M. rosae.

\section{Adesmus beruri sp. nov.}

$$
\text { (Fig. 2) }
$$

Etimologia. O substantivo específico em aposição refere-se à localidade-tipo.

Tegumento, em geral, preto a castanho-escuro. Palpos e pernas com tegumento amarelado. Cabeça, com manchas pequenas de pubescência branca: uma atrás da inserção do escapo e outra, arredondada, na área genal junto ao lobo ocular inferior. Lobos oculares superiores tão afastados entre si quanto quase o dobro da largura de um lobo. Antenas ultrapassam os ápices elitrais na base do antenômero VIII.

Protórax revestido por pubescência branca, densa, menos no processo prosternal. Pronoto com pequena mancha de pubescência preta, central, localizada um pouco atrás do meio. Escutelo coberto por densa pubescência branca.

Élitros revestidos por pubescência branca com três faixas transversais de pubescência preta que vão da carena à sutura (Fig. 2): uma no sexto basal, outra à frente do meio e a terceira no terço apical; uma quarta faixa preta antes do ápice, da sutura até a margem (élitro esquerdo) ou até o meio do dorso (élitro direito). Nos lados dos élitros, entre a carena e a epipleura, manchas de pubescência branca: subumeral, no nível do terço anterior (não atinge a margem); pequena, atrás do meio e uma outra prolongada até o ápice.

Pubescência branca da face ventral reveste: mesepimeros, mesepisternos, metepisternos, metasterno e ápice dos urosternitos I-IV.

Dimensões em mm. Comprimento total, 9,1; comprimento do protórax, 1,8; maior largura do protórax, 2,3; comprimento do élitro, 6,4; largura umeral, 2,8.

Material-tipo. Holótipo +, BRASIL, Amazonas: Beruri (Rio Purus, 0356'S, 61 $21^{\circ} 21^{\prime}$ W), X.2002, F. F. Felipe Filho \& U. C. Barbosa col., varredura (INPA).

Discussão. O padrão do colorido elitral com faixas estreitas, pretas ou avermelhadas, encontra-se também em Adesmus tribalteatus (Bates, 1881), A. juninensis Galileo \& Martins, 1999 e A. phoebinus (Aurivillius, 1900). Adesmus beruri sp. nov. difere de todas pela cabeça preta e pela única mancha pequena, preta, no centro-posterior do pronoto. Nas outras espécies, a cabeça é revestida por pubescência branca e o pronoto ou tem faixa longitudinal ou duas manchas escuras. Em A. tribalteatus, a faixa preto-avermelhada próxima da base dos élitros é oblíqua e não há uma quarta faixa apical; em A. beruri, essa faixa é reta e existe uma quarta faixa preta apical.

\section{Cotycuara villosa sp. nov. \\ (Fig. 3)}

Etimologia. O adjetivo específico do latim, villosum = viloso, significa provido de pelos abundantes, referente á pubescência densa na cabeça e no pronoto.

Colorido geral castanho-escuro a castanhoavermelhado. Clípeo amarelado. Peças bucais amareladas, exceto o último artículo dos palpos, preto com a região basal amarelada. Face inferior do escapo e do antenômero III parcialmente castanho-amarelados; antenômeros II, III e VII-X com anel basal amarelado, antenômeros IV-VI amarelados com região apical acastanhada; XI inteiramente castanho-escuro. Coxas amareladas; pro- e mesofêmures amarelados com anel apical castanhoescuro; metafêmures castanhos com a base amarelada; tarsômeros I e II amarelados no meio; base do tarsômero V amarelada. Pubescência branco-amarelada, densa: porção centro-superior da fronte e entre os tubérculos anteníferos; no vértice até o estreitamento entre os lobos oculares inferiores; nos lados do protórax e no disco pronotal, exceto mancha castanho-escura, subtriangular, no centro do terço basal.

Élitros com faixa sutural estreita de pubescência branco-amarelada, longa. Friso epipleural com pelos amarelo-esbranquiçados, mais longos. Carena elitral bem projetada do úmero ao sexto apical. Cada élitro, com extremidade subarredondada. Urosternitos acastanhados. Último urosternito com entalhe central.

Dimensões em mm. Comprimento total, 12,8; comprimento do protórax, 2,3; maior largura do protórax, 3,2; comprimento do élitro, 10,0; largura umeral, 4,0.

Material-tipo. Holótipo + , COSTA RICA, Puntarenas: (Reserva Monteverde), 03.VI.1992, F. Andrews \& A. Gilbert col. (ACMS).

Discussão. Cotycuara villosa sp. nov., pelo escapo amarelado no lado interno é discriminada no item $1 \mathrm{da}$ chave para espécies (GAlileo \& Martins, 2005) junto com C. albomarginata. Cotycuara villosa separa-se de C. albomarginata pelo vértice revestido por pubescência branco-amarelada; pelo pronoto coberto por pubescência branco-amarelada, menos numa área centro-basal acastanhada; pela pubescência branca restrita ao friso epipleural e pelos urosternitos II a IV, acastanhados. Em C. albomarginata o vértice tem duas faixas acastanhadas atrás dos lobos oculares superiores, o pronoto tem pubescência branco-amarelada restrita aos lados e a faixa de pubescência amarelo-esbranquiçada dos élitros ocupa toda área da carena à epipleura.

\section{Phoebe parvimacula sp. nov. (Fig. 4)}

Etimologia. $\mathrm{O}$ adjetivo específico do latim, parvus $=$ pequeno e macula $=$ mancha; alusivo às pequenas manchas pretas dos élitros.

Tegumento, em geral, castanho-escuro. Cabeça revestida por pubescência branca, exceto em dois 
tubérculos frontais com pubescência acastanhada. Olhos inteiros, com emarginação muito profunda. Escapo preto; pedicelo e demais antenômeros avermelhados.

Protórax coberto por pubescência branca e glabro nas seguintes áreas: mancha arredondada no centro do pronoto; manchas arredondadas laterais à frente do meio do pronoto; faixa estreita longitudinal nos lados, da base ao ápice; faixa transversal entre a coxa e a faixa longitudinal nos lados.

Élitros cobertos por pubescência branca menos nas áreas desnudas com tegumento castanho-escuro: duas dorsais no sexto basal; duas menores, dorsais, pouco à frente do meio; duas justapostas na sutura, arredondadas em conjunto no meio; duas dorsais, arredondadas, no terço apical; duas coalescentes na sutura, arredondadas em conjunto, pouco menores que a central, no quarto apical; duas alongadas, oblíquas da margem para a sutura e duas em sentido inverso (quase justapostas em "V" invertido), na região anteapical. Carena elitral evidente; epipleuras com pubescência branca e quatro manchas pequenas desnudas soldadas na carena: uma no quarto basal, duas para trás do meio e uma no ápice da carena. Extremidades elitrais arredondadas.

Face ventral revestida por pubescência branca, mais esparsa no meio do metasterno e dos urosternitos. Área em torno da sutura metepisternal glabra. Pernas amareladas.

Dimensões em mm. Comprimento total, 10,6-10,9; comprimento do protórax, 1,7-1,8; maior largura do protórax, 1,6-1,7; comprimento do élitro, 7,8-7,9; largura umeral, 2,1-2,3.

Material-tipo. Holótipo ơ, BOLÍVIA, Santa Cruz: Buena Vista (3,7 km SSE, Hotel Flora \& Fauna, $430 \mathrm{~m})$, 14-19.X.2000, M. C. Thomas col., tropical transition forest (MNKM). Parátipo o', mesma localidade do holótipo, 14-16.X.2000, R. Morris col. (ACMS).

Discussão. Phoebe parvimacula sp. nov. caracteriza-se pela fronte dos machos com tubérculos, escapo castanho-escuro, pronoto com três manchas glabras e manchas elitrais pequenas. Pronoto com três manchas glabras, entre a pubescência esbranquiçada, também ocorre em $P$. tinga Martins \& Galileo 1998 e $P$. ornator (Tippman, 1960). Phoebe parvimacula distinguese de $P$. tinga pela fronte dos machos com tubérculos e pela presença de máculas acastanhadas, justapostas na sutura dos élitros (Fig. 4). De P. ornator, difere pelas manchas pronotais e elitrais menores e pela ausência de mancha acastanhada na região antiapical dos élitros que

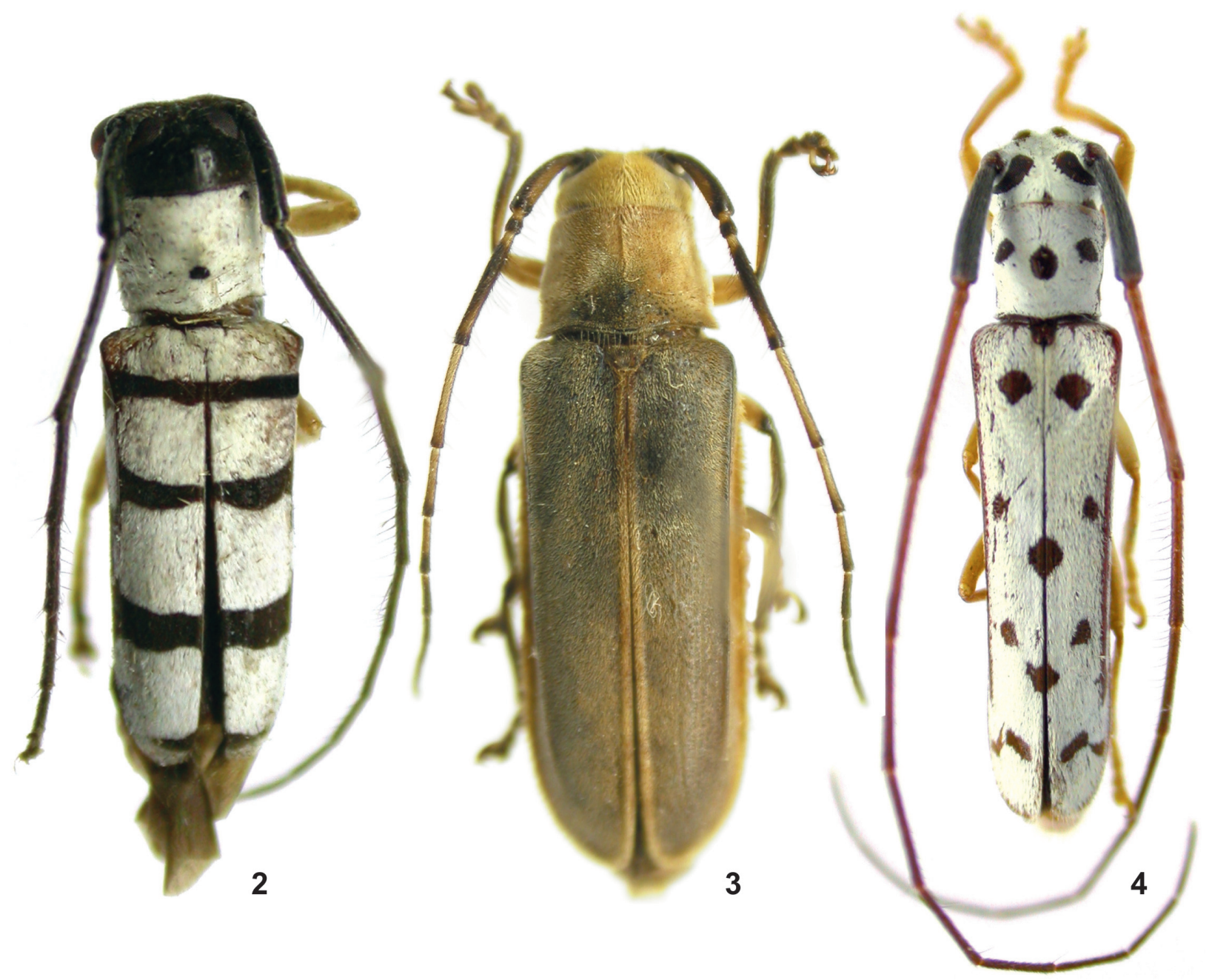

Figuras 2-4. 2, Adesmus beruri sp. nov., holótipo fêmea, comprimento 9,1 mm; 3, Cotycuara villosa sp. nov., holótipo fêmea, comprimento $12,8 \mathrm{~mm} ; 4$, Phoebe parvimacula sp. nov., holótipo macho, comprimento $10,6 \mathrm{~mm}$. 
são arredondados. Em $P$. tinga, descrita da Argentina, a cabeça dos machos é provida de cornos e não existem manchas escuras suturais. Em P. ornator, também descrita da Bolívia, as manchas elitrais são desenvolvidas e estão presentes nas extremidades elitrais que são truncadas com espículo externo.

Agradecimentos. A James Wappes (ACMS) e Augusto Loureiro Henriques (INPA), pelo empréstimo de material para estudo; a Rejane Rosa, Museu de Ciências Naturais, Fundação Zoobotânica do Rio Grande do Sul (MCNZ) pela ilustração; a Eleandro Moysés, bolsista IC/CNPq/FZB (MCNZ) pelas fotografias e tratamento digital; a Erica H. Buckup, pela leitura crítica do texto. Ao CNPq e FAPEAM pelo auxílio financeiro ao Programa de Apoio a Núcleos de Excelência (Pronex) projeto "Amazonas: diversidade de insetos ao longo de suas fronteiras (Processo 1437/ 207)" coordenado por José Albertino Rafael (INPA). Ao CNPq pela bolsa de pesquisa.

\section{REFERENCIAS}

Bezark, L. G. 2010. A photograph catalog of the Cerambycidae of the New World. Disponível em: <http://plant.cdfa.ca.gov/byciddb/default.app>. Acesso em: 06.06 .2010 .
Gahan, C. J. 1892. Additions to the Longicornia of Mexico and Central America, with notes on some previously-recorded species. Transactions of the Entomological Society of London 1892:255-274.

Galileo, M. H. M. \& Martins, U. R. 1999. O gênero Adesmus Lepeletier \& A.-Serville, 1825 (Coleoptera, Cerambycidae, Lamiinae, Hemilophini). Iheringia, Série Zoologia (86):77-116.

2004. Novos táxons em Hemilophini (Coleoptera, Cerambycidae) com única carena elitral. Iheringia, Série Zoologia 94(4):381-388

2005. Novos táxons de Hemilophini (Coleoptera, Cerambycidae, Lamiinae) sem carenas nos élitros da região Neotropical. Revista Brasileira de Entomologia 49(1):63-68.

Martins, U. R. \& Galileo, M. H. M. 1991. Gêneros de Hemilophini relacionados com Malacoscylus Thomson, 1868. Revista Brasileira de Entomologia 35(3):619-629.

1998. Gêneros de Hemilophini semelhantes a Phoebe. Revista Brasileira de Entomologia 41(2-4):431-437. 2004. Sobre Hemilophini (Lamiinae) da Região Neotropical: espécies novas e novos registros. Revista Brasileira de Zoologia 21(3):535-541.

Monné, M. A. \& Bezark, L. G. 2009. Checklist of the Cerambycidae, or longhorned wood-boring beetles, of the Western Hemisphere. Rancho Dominguez (CA), BioQuip. 2010 version. 463 p.

Recebido em julho de 2010. Aceito em outubro de 2010. ISSN 0073-4721

Artigo disponível em: www.scielo.br/isz

Impresso e distribuído em 2011. 